\section{Control of Clostridium difficile-associated diarrhea by antibiotic stewardship in a small community hospital}

\section{To the editor:}

Clostridium difficile-associated diarrhea (CDAD) is an important nosocomial infection in Canadian hospitals and an emerging public health problem. CDAD causes significant morbidity and can be associated with high all-cause mortality (1). Recent Ontario guidelines have emphasized housekeeping and case-management strategies to control CDAD (2). Although antibiotic stewardship has been suggested by many experts as useful in CDAD control (3-5), this strategy has not been included in the Ontario recommendations. We describe a persistent outbreak of CDAD in a small hospital that appears to have been controlled by a simple antibiotic stewardship program.

Campbellford Memorial Hospital (CMH) is a small (34 bed) community hospital in rural eastern Ontario. $\mathrm{CMH}$ does not perform dialysis or operate a true intensive care unit (ie, no ventilators or invasive hemodynamic monitoring). Patient care areas were built in 1953, most rooms have shared toilets and occupancy rates were close to $100 \%$ throughout the outbreak period.

Before April 2007, CMH experienced sporadic incident nosocomial cases of CDAD (frequent loose stools and stool positive for $\mathrm{C}$ difficle toxin with either onset of symptoms $>72 \mathrm{~h}$ after hospital admission or a history of hospital admission within the previous four weeks) (6). The average infection rate was $0.3 / 1000$ patient days (approximately one case every three months) over the 21 months before April 2007. Beginning in April 2007, CMH experienced much higher rates of incident nosocomial CDAD. Over a 15-month period (April 2007 to June 2008), CMH had 49 incident nosocomial cases of CDAD with an average infection rate of 3.2/1000 patient days (Figure 1). This was a very high rate compared with other Ontario hospitals (average Ontario CDAD infection rate in August 2008 was 0.39/1000 patient days/month) (7). Forty-seven cases ( $88 \%$ ) had a history of hospital antibiotic use, $35(71 \%)$ fluoroquinolone use and 28 (57\%) moxifloxicin use.

$\mathrm{CMH}$ followed expert advice and implemented a series of housekeeping and patient management measures without controlling the outbreak (Table 1). On June 17, 2008 the CMH instituted several additional measures. These included double cleaning of CDAD patient rooms seven days a week (previously five days a week), disposable bedpans for CDAD cases and an antibiotic stewardship program. The latter consisted of two elements. First, memos were sent to physicians and notices were posted requesting that they avoid the use of fluoroquinolones for inpatients. There was special emphasis on reducing moxifloxacin use because of the particularly strong association with this antibiotic (8). Second, all orders for moxifloxacin for inpatients were automatically reviewed by the hospital pharmacist and consultant internist, and alternative antibiotics recommended to the most responsible physician (9).

The use of moxifloxacin declined from an average of 87 doses per month during the 14 months of the outbreak to an average of 12 doses per month - an $87 \%$ decrease - in the first six months after implementation of the antibiotic stewardship program.

$\mathrm{CMH}$ has had one incident case of nosocomial CDAD in the 24 months from June 17, 2008 until July, 2010. This was a significant decrease in the CDAD rate from 3.2/1000 patient days/month (before implementation of antibiotic stewardship) to $0.04 / 1000$ patient days/month (over the 24 months with antibiotic stewardship) (incidence rate ratio associated with the intervention 0.013 [95\% CI 0.018 to 0.093]; $\mathrm{P}<0.0001$ [ $\chi^{2}$ test]). CMH's simple antibiotic stewardship program was effective at changing antibiotic use and may have played a decisive role in ending a persistent CDAD
TABLE 1

Clostridium difficile-associated diarrhea (CDAD) control interventions

\begin{tabular}{lll}
\hline & Date & Interventions \\
\hline A & September & $\cdot$ Increased infection control \\
& 2007 & $\cdot$ Staff education \\
& & - Provincial CDAD control standards implemented \\
B $\quad$ March 2008 & $\cdot$ Infection control practitioner hired \\
C $\quad$ June 2008 & • Double cleaning CDAD rooms increased from 5/7 to 7/7 \\
& & - Antibiotic stewardship implemented \\
\hline
\end{tabular}

5/7 Five days a week; 7/7 Seven days a week

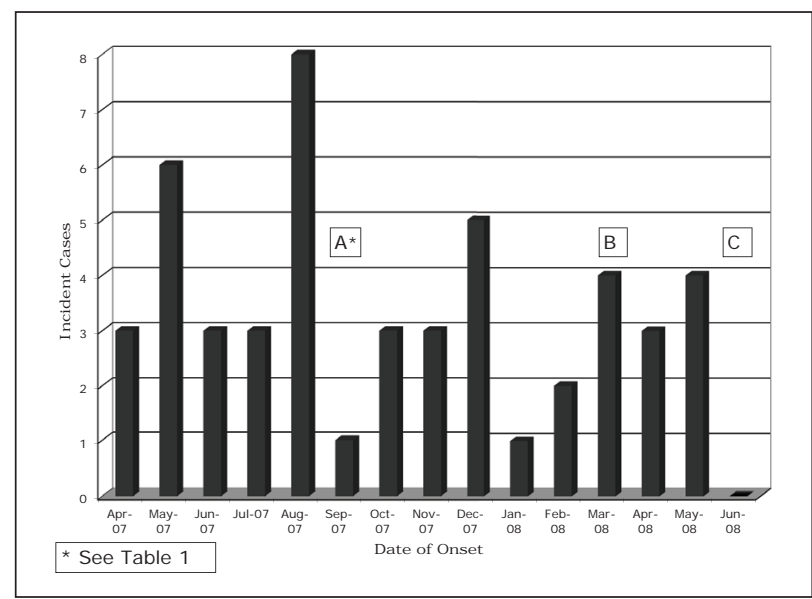

Figure 1) Clostridium difficile-associated diarrhea outbreak at Campbellford Memorial Hospital (Trent Hills, Ontario) April 2007 to May 2008

outbreak. Additional environmental measures, adopted at the same time as antibiotic stewardship, may have also contributed. Antibiotic stewardship deserves more attention as a CDAD control strategy.

A particularly strong link between moxifloxacin and CDAD has been proposed by other observers (8). This association could be related to moxifloxacins's activity against anaerobes, unique among the currently available fluoroquinolones (10). The apparent association between CDAD and moxifloxacin use deserves further investigation.

ACKNOWLEDGEMENTS: The authors acknowledge the work of Marilyn Petherick RN ICP in compiling the data for this report.

\section{REFERENCES}

1. Pépin J, Valiquette L, Cossette B. Mortality attributable to nosocomial Clostridium difficile-associated disease during an epidemic caused by a hypervirulent strain in Quebec. CMAJ 2005;173:1037-42.

2. Provincial Infectious Diseases Advisory Committee. Best Practices Document for the Management of Clostridium difficile in all health care settings. Ontario Ministry of Health and LongTerm Care. January 2009. <www.health.gov.on.ca/english/ providers/program/infectious/diseases/best_prac/bp_cdiff.pdf> (Accessed May 18, 2012).

3. Vonberg RP, Kuijper EJ, Wilcox MH, et al. Infection control measures to limit the spread of Clostridium difficile. Clin Microbiol Infect 2008;Suppl 5:2-20.

4. Labbe, AC, Poirier L, Maccannell D, et al. Clostridium difficile infections in a Canadian tertiary care hospital before and during a regional epidemic associated with the B1/NAP1/027 strain. Antimicrob Agents Chemother 2008;52:3180-7. 
5. DuPont HL, Garey K, Caeiro JP, Jiang ZD. New advances in Clostridium difficile infection; changing epidemiology, diagnosis, treatment and control. Curr Opin Infect Dis 2008;21:500-7.

6. Control of Clostidium difficile infection (CDI) outbreaks in hospitals. A guide for hospital and health unit staff: Public Health Division, Ministry of Health and Long-Term Care. December 2009: 9-10.

7. Patient Safety Indicator Reporting: Ontario Trends. <www.ontla. on.ca/library/repository/mon/23001/289349.pdf> (Accessed May 18, 2012).

8. Gallagher JC, Du JK, Rose C. Severe pseudomembranous colitis after moxifloxacin use: A case series. Ann Pharacother 2009;43:123-8.

9. Low DE. Treatment of community acquired pneumonia. CMAJ 2008;179:1245-6.

10. Spangler SK, Jacobs MR, Appelbaum PC. Activity of CP 99,219 compared with those of ciprofloxacin, grepafloxacin, metronidazole, cefoxitin, piperacillin and piperacillin-tazobactam against 489 anerobes. Antimicrob Agents Chemother 1994;38:2471-6.

Alice Schabas is a fourth year medical student at Queen's University, Kingston, Ontario

David N Fisman is an Associate Professor of Epidemiology and Health Policy at the Dalla Lana School of Public Health, University of Toronto, Toronto Ontario

Richard Schabas is consultant internist at Campbellford Memorial Hospital and Medical Officer of Health for the Hastings and Prince Edward Counties Health Unit This work originated from Campbellford Memorial Hospital 


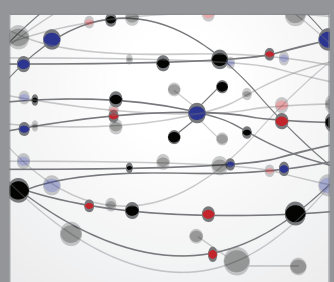

The Scientific World Journal
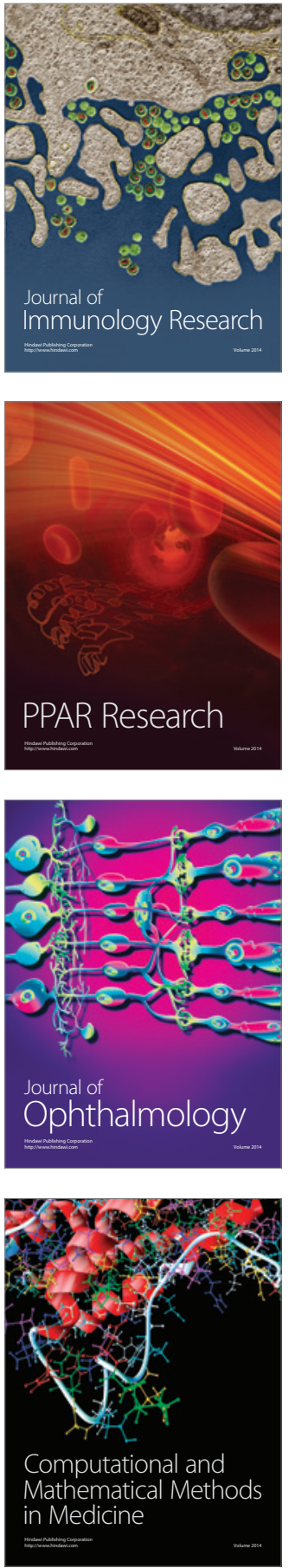

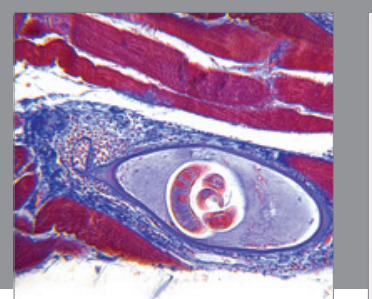

Gastroenterology Research and Practice

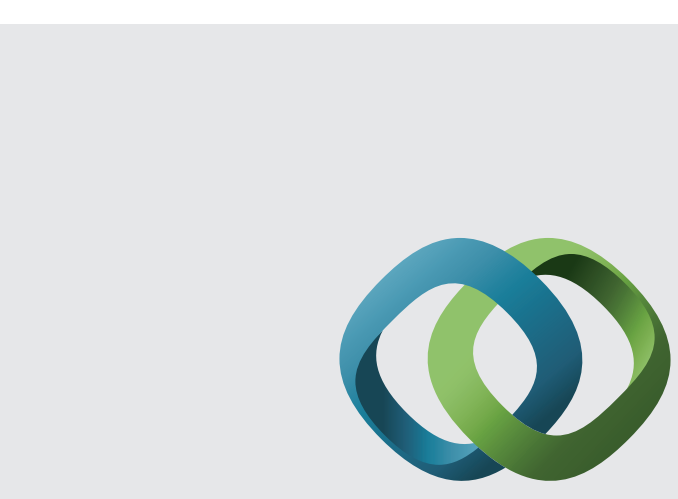

\section{Hindawi}

Submit your manuscripts at

http://www.hindawi.com
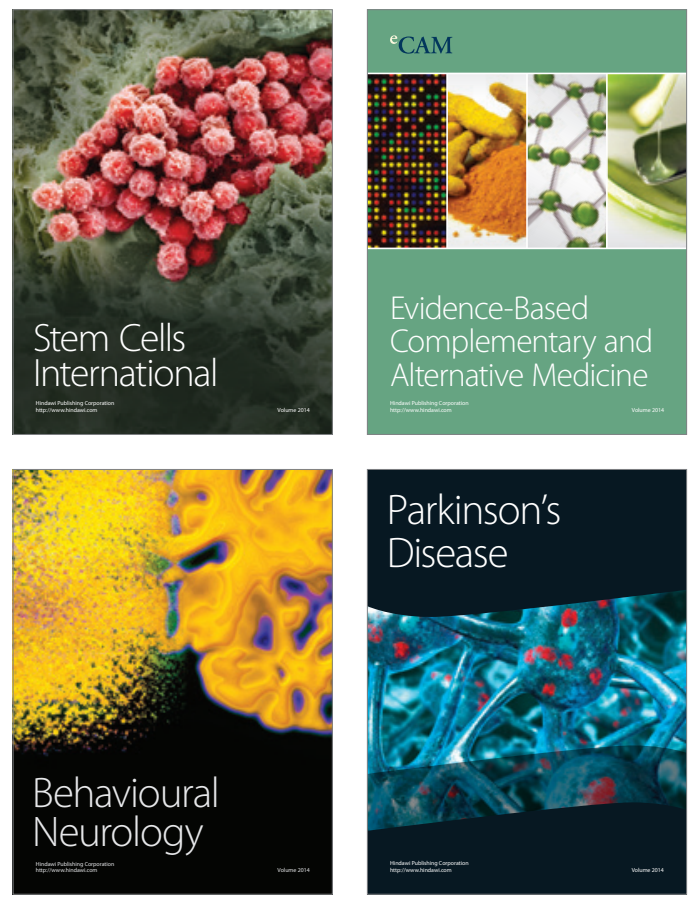
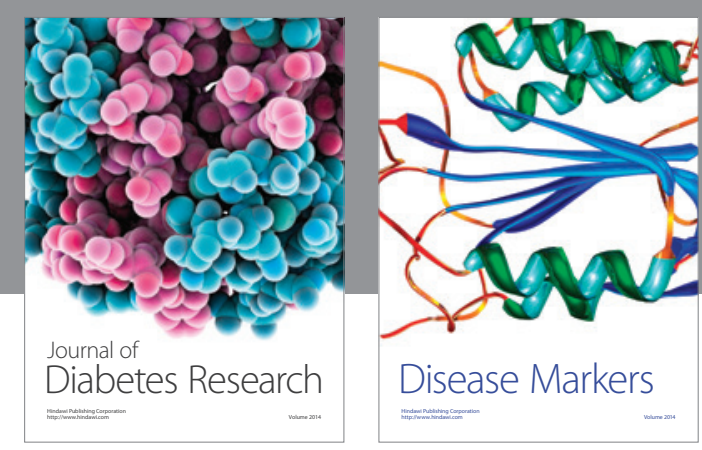

Disease Markers
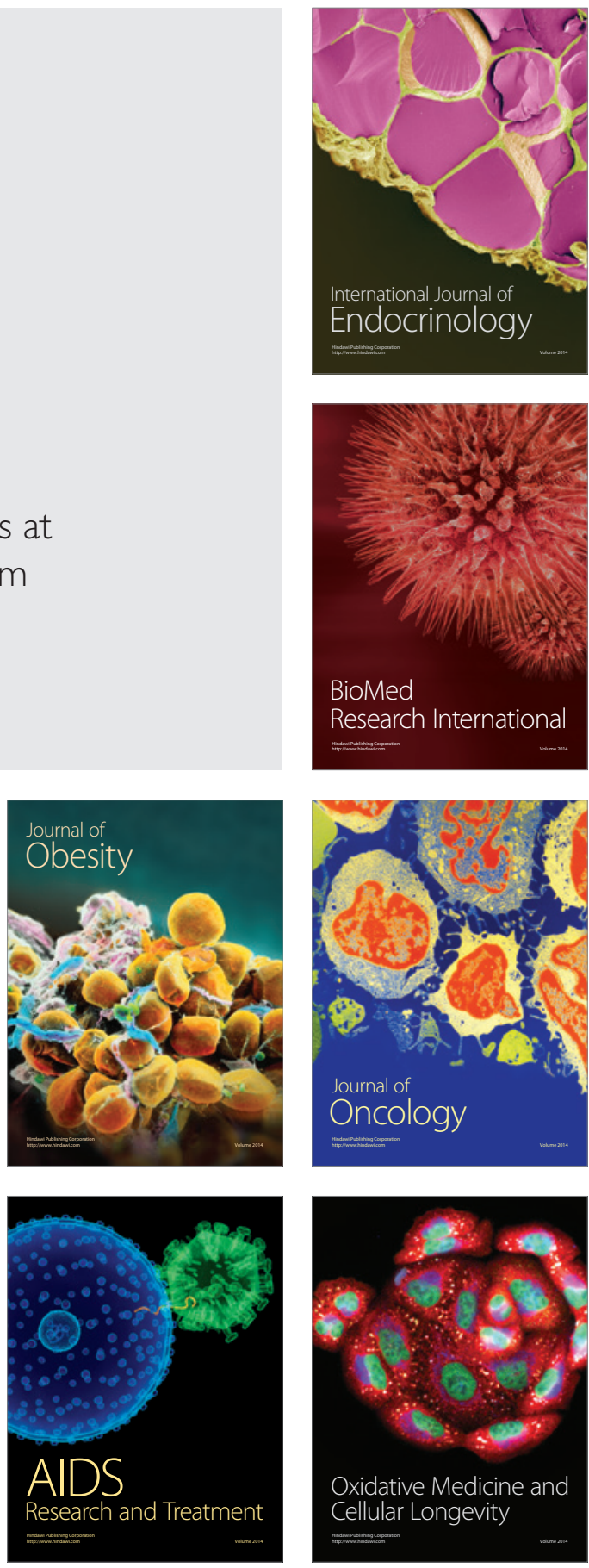